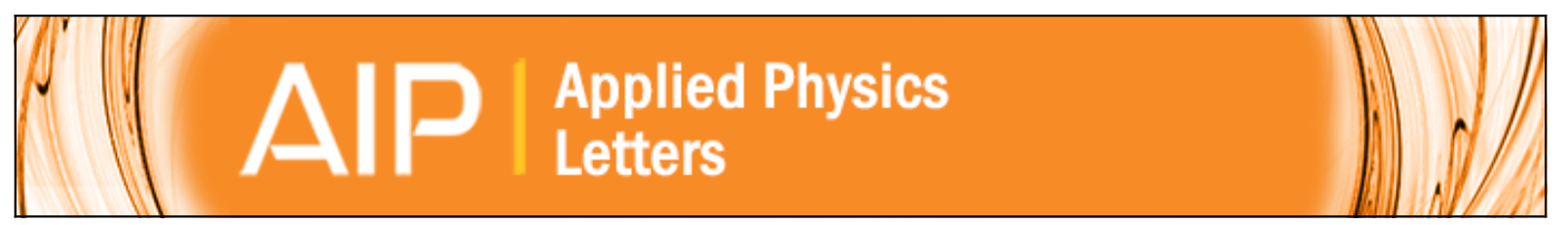

\title{
Efficient, air-stable colloidal quantum dot solar cells encapsulated using atomic layer deposition of a nanolaminate barrier
}

Alexander H. Ip, André J. Labelle, and Edward H. Sargent

Citation: Applied Physics Letters 103, 263905 (2013); doi: 10.1063/1.4858135

View online: http://dx.doi.org/10.1063/1.4858135

View Table of Contents: http://scitation.aip.org/content/aip/journal/apl/103/26?ver=pdfcov

Published by the AIP Publishing

\section{Articles you may be interested in}

Air-stable short-wave infrared $\mathrm{PbS}$ colloidal quantum dot photoconductors passivated with $\mathrm{Al} 2 \mathrm{O} 3$ atomic layer deposition

Appl. Phys. Lett. 105, 171110 (2014); 10.1063/1.4900930

Thin-film encapsulation of inverted indium-tin-oxide-free polymer solar cells by atomic layer deposition with improvement on stability and efficiency

Appl. Phys. Lett. 101, 233902 (2012); 10.1063/1.4769355

Metal/III-V effective barrier height tuning using atomic layer deposition of high-K/high-k bilayer interfaces

Appl. Phys. Lett. 99, 092107 (2011); 10.1063/1.3633118

The origin of low water vapor transmission rates through Al 2 O 3 / ZrO 2 nanolaminate gas-diffusion barriers grown by atomic layer deposition

Appl. Phys. Lett. 96, 243308 (2010); 10.1063/1.3455324

Encapsulation of pentacene/ C 60 organic solar cells with Al 203 deposited by atomic layer deposition Appl. Phys. Lett. 90, 253511 (2007); 10.1063/1.2751108

\section{AIP $\mid$ APL Photonics}

APL Photonics is pleased to announce Benjamin Eggleton as its Editor-in-Chief

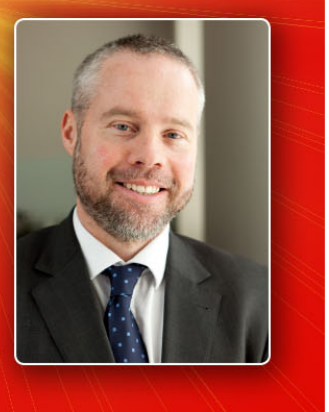




\title{
Efficient, air-stable colloidal quantum dot solar cells encapsulated using atomic layer deposition of a nanolaminate barrier
}

\author{
Alexander H. Ip, André J. Labelle, and Edward H. Sargent ${ }^{\text {a) }}$ \\ Department of Electrical and Computer Engineering, University of Toronto, 10 King's College Road, \\ Toronto, Ontario M5S 3G4, Canada
}

(Received 10 September 2013; accepted 12 December 2013; published online 26 December 2013)

\begin{abstract}
Atomic layer deposition was used to encapsulate colloidal quantum dot solar cells. A nanolaminate layer consisting of alternating alumina and zirconia films provided a robust gas permeation barrier which prevented device performance degradation over a period of multiple weeks. Unencapsulated cells stored in ambient and nitrogen environments demonstrated significant performance losses over the same period. The encapsulated cell also exhibited stable performance under constant simulated solar illumination without filtration of harsh ultraviolet photons. This monolithically integrated thin film encapsulation method is promising for roll-to-roll processed high efficiency nanocrystal solar cells. (C) 2013 AIP Publishing LLC. [http://dx.doi.org/10.1063/1.4858135]
\end{abstract}

Solar cells employing colloidal quantum dots (CQDs) have attracted great interest due to their potential for low cost, large area fabrication of high efficiency modules. ${ }^{1,2}$ CQDs are nanocrystals synthesized in and processed from solution, allowing for ease of fabrication as well as fine control over the final size distribution of particles. Changing the diameter of the nanocrystals tunes the band gap and therefore the absorption range. CQD solar cells can be tuned to absorb across the entirety of the solar spectrum, which extends into the infrared range. The power conversion efficiency (PCE) of this technology has been extended to greater than $7 \% .^{3-5}$

However, the high internal surface area of CQD solids renders them vulnerable to oxidation which can degrade device performance. ${ }^{6-8}$ Storage, testing, and fabrication of CQD devices are often performed under inert atmospheres, such as $\mathrm{N}_{2}$, in order to mitigate these effects. For practical deployment of CQD solar cells, however, it is necessary to develop effective encapsulation methods to prevent degradation of performance.

Thin film encapsulation by atomic layer deposition (ALD) is an attractive approach as it is lightweight and rollto-roll compatible, ${ }^{9,10}$ unlike sealing with glass. ALD can be used to controllably deposit conformal, nanoscale films through sequential, self-limiting reactions between precursors. ${ }^{11}$ Briefly, the technique involves exposure of the substrate to one precursor, which adsorbs in a monolayer while excess is purged from the reaction chamber. This is followed by introduction of the second precursor, which reacts with the initially adsorbed material, forming a single layer of the desired film. This can be repeated until the required thickness is reached. ALD encapsulation has been demonstrated in various thin film inorganic and organic electronic devices, ${ }^{12-16}$ particularly using $\mathrm{Al}_{2} \mathrm{O}_{3}$ as the permeation barrier.

The conformal nature of ALD has been exploited to infiltrate nanocrystalline CQD films, with benefits to stability and mobility. ${ }^{17,18}$ ALD alumina has also been used for low temperature encapsulation of photovoltaic CQD solids. ${ }^{19}$

\footnotetext{
${ }^{\text {a) }}$ Author to whom correspondence should be addressed. Electronic mail: ted.sargent@utoronto.ca
}

However, the performance achieved, while stable, was around $2 \%$, well below record performance for this materials system. Additionally, the processing time for depositing such encapsulating films was quite long, at around $10 \mathrm{~h}$ due to the long purge times required both for infiltration of nanocrystalline solids and to ensure formation of conformal, pinhole-free barriers at low temperature.

We initially attempted encapsulation of a high efficiency device using a pure alumina ALD film, though shorter purge times were used to enable commercially acceptable processing times. However, we found that performance depended on the testing atmosphere, indicating that there were imperfect gas permeation barrier properties of our film. The near instantaneous effect due to change in testing atmosphere indicated that oxygen was able to rapidly access the CQD surfaces, possibly through imperfections in the film coverage. It is also known that ALD alumina is susceptible to corrosion by water, ${ }^{20,21}$ particularly films deposited at low temperature due to incorporated hydrogen. ${ }^{22}$

We sought therefore a thin film encapsulation method that would be less vulnerable to bulk water, could be deposited relatively quickly, and would maintain high efficiency performance of a CQD solar cell. With this in mind, we turned to the concept of ALD nanolaminates, multilayer stacks of alternating nanoscale materials that have previously been reported to offer superior physical properties compared with the constituent materials. ${ }^{23,24} \mathrm{We}$ looked in particular to a combined $\mathrm{Al}_{2} \mathrm{O}_{3}$ and $\mathrm{ZrO}_{2}$ nanolaminate which had been reported to possess improved barrier properties over neat $\mathrm{Al}_{2} \mathrm{O}_{3}$ while being deposited below $100^{\circ} \mathrm{C}$. $^{21,25,26}$

CQD solar cells were fabricated similarly to previous reports $^{3}$ with a device architecture composed of: fluorinedoped tin oxide $/ \mathrm{TiO}_{2}(50 \mathrm{~nm}) / \mathrm{PbS}$ CQDs $(350 \mathrm{~nm}) / \mathrm{MoO}_{3}$ $(40 \mathrm{~nm}) / \mathrm{Au}(160 \mathrm{~nm})$ as shown in Figure 1(a). The CQDs were spin-cast in a layer-by-layer approach with a solid-state ligand exchange leading to dense films of disordered particles. Deposition of the nanolaminate barrier ${ }^{21}$ was performed in a glovebox integrated ALD system (Savannah S100, Cambridge Nanotech, Inc.) at a chamber temperature of $80^{\circ} \mathrm{C}$ and a nitrogen carrier gas flow of $20 \mathrm{sccm}$. The film was 
(a)

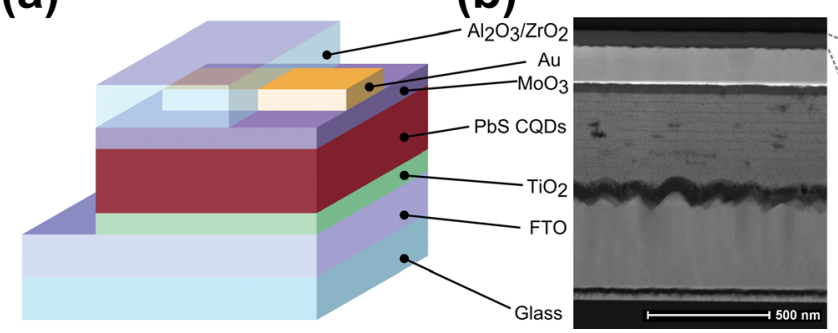

composed of 15 "supercycles," each comprising 20 cycles of alumina followed by 20 cycles of zirconia. Each alumina cycle consisted of a $15 \mathrm{~ms}$ pulse of trimethylaluminium with a $5 \mathrm{~s}$ purge time, followed by a $15 \mathrm{~ms}$ pulse of $\mathrm{H}_{2} \mathrm{O}$ with a $5 \mathrm{~s}$ purge time. The zirconia cycles involved a $300 \mathrm{~ms}$ pulse of tetrakis(dimethylamido)zirconium(IV) with a $7 \mathrm{~s}$ purge time, followed by a $30 \mathrm{~ms}$ pulse of $\mathrm{H}_{2} \mathrm{O}$ with a $7 \mathrm{~s}$ purge time.

A cross sectional transmission electron micrograph (TEM) is shown in Figure 1(b), with each layer of the device labeled. At this scale, the individual quantum dots are not visible; the density of $3.1 \mathrm{~nm}$ quantum dots is approximately $1.5 \times 10^{19} \mathrm{~cm}^{-3} \cdot{ }^{27}$ A close-up of the encapsulation layer is shown in Figure 1(c). The total thickness of the barrier is approximately $70 \mathrm{~nm}$, similar to the thickness of the initially attempted alumina. The component layers of the nanolaminate stack are clearly visible, demonstrating controlled, conformal coating. The brighter layers correspond to the zirconia films, each about $3.5 \mathrm{~nm}$ thick, while the darker areas indicate alumina, with each layer approximately $1.5-2 \mathrm{~nm}$ thick. Some alloying of materials does occur at each interface, so it is difficult to determine precise thicknesses. These dense interfacial phases may be responsible for improved performance of multilayer permeation barriers. ${ }^{26}$

To validate the barrier properties of the nanolaminate layer, we compared the encapsulated device performance against an identically prepared, unencapsulated control device under air and $\mathrm{N}_{2}$ atmospheres. The current density-voltage (J-V) characteristics were measured using a Keithley 2400 source-meter under simulated AM 1.5 illumination using a Xe lamp and filters (Sciencetech) within class A specifications. The source intensity was measured using a broadband power meter (Melles-Griot) and confirmed using a calibrated Si reference solar cell (Newport).

The J-V curves for the control device are shown in Figure 2(a). Under $\mathrm{N}_{2}$ flow, the cell shows good performance, but testing under air results in a drastically degraded performance. This effect is reversible, suggesting a role of physisorbed (c)

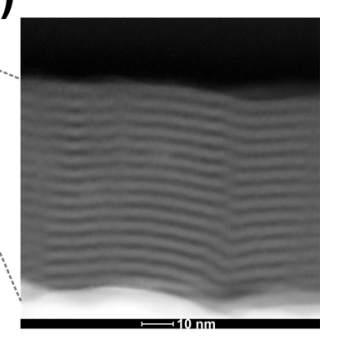

FIG. 1. Device. (a) Schematic of device architecture. (b) TEM image of device structure. Stratification of the dense $\mathrm{PbS}$ CQD layer is apparent due to the layer-by-layer deposition. (c) Detailed TEM view of encapsulation layer. The lighter layers correspond to zirconia while the darker layers are alumina.

oxygen or moisture. Similar behaviour was seen with pure alumina used as an encapsulant. In contrast, the nanolaminate encapsulated cell shows identical J-V characteristics (Figure 2(b)) regardless of testing atmosphere. The barrier is therefore pinhole free and able to prevent external gases from reaching the active device. The change in open circuit voltage $\left(\mathrm{V}_{\mathrm{OC}}\right)$ and short circuit current density $\left(\mathrm{J}_{\mathrm{SC}}\right)$ compared to control are attributed to the mild annealing during the ALD process as has been shown previously. ${ }^{28}$

Next, we tested the stability of the encapsulated cell when stored in air and compared it with unencapsulated devices stored in air or in an $\mathrm{N}_{2}$-filled glovebox. All devices were stored at open-circuit in the dark, with the J-V characteristics measured as described previously intermittently throughout a two week period. Figure 3(a) shows the relative change in PCE compared with the initial testing for the different devices. In all cases, the encapsulated device was measured under air while the unencapsulated devices were measured under nitrogen flow.

As expected, the unencapsulated device stored in air degraded rapidly, before saturating at under $50 \%$ of the initial efficiency after 5 days. In contrast with the reversible effects seen in Figure 2(a), this degradation suggests a permanent loss due to oxidative attack of the CQD surfaces. Even the glovebox-stored control sample exhibited a gradual decline in performance over the course of the study. This may be attributed to the brief air exposure the device experiences between the storage glovebox and the testing set-up, or it could point to even small amounts of oxygen or moisture present in the glovebox atmosphere leading to degradation.

The encapsulated sample, however, showed a very good stability over the experiment with a PCE that remained very near the initial value. Since even the nitrogen stored device exhibited some slow degradation with minimal air exposure, this indicates that the nanolaminate maintained complete isolation of the CQD device from atmospheric conditions over two weeks.

(a)

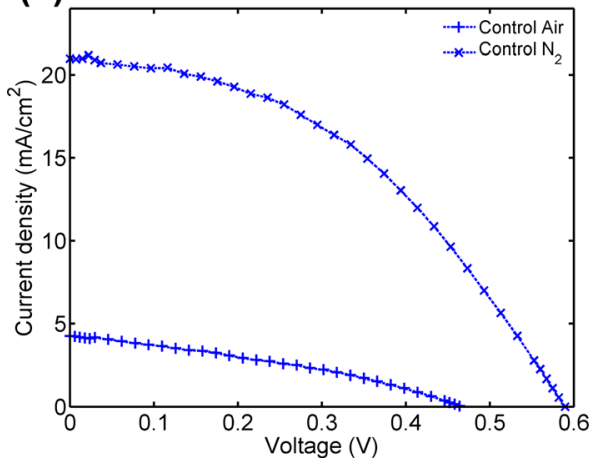

(b)

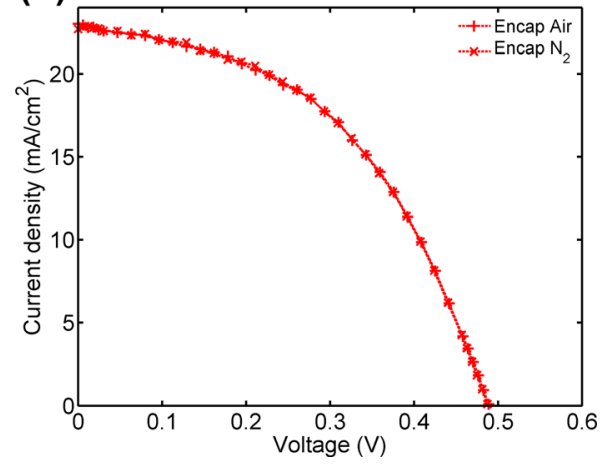

FIG. 2. Atmospheric insensitivity. (a) $\mathrm{J}-\mathrm{V}$ characteristics of an unencapsulated device measured under air and nitrogen atmospheres. (b) J-V characteristics of nanolaminate encapsulated device measured under air and nitrogen atmospheres. 
(a)

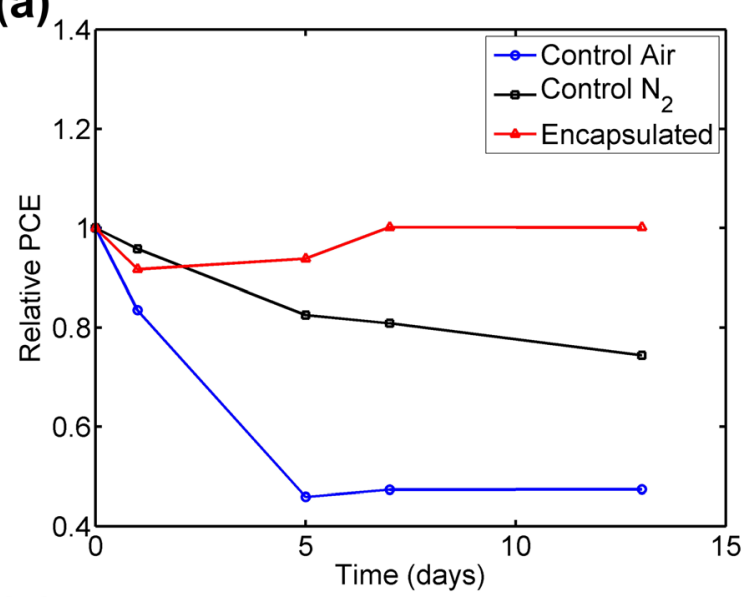

(b)

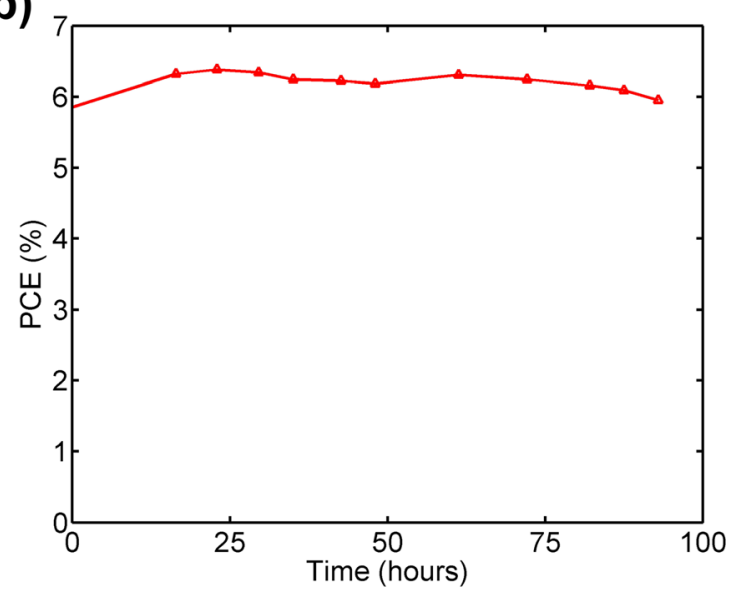

FIG. 3. Stability. (a) The relative PCE over time compared with initial measurements for an encapsulated device stored in air and unencapsulated devices stored in air and nitrogen environments. All devices were stored in the dark between measurements. (b) The PCE of an encapsulated device under constant AM 1.5 illumination.

Finally, the stability of the encapsulated device was tested under long term constant illumination to observe any photodegradation effects. An encapsulated device that had been stored in air without measurement for 3 weeks was used. It was illuminated as described above and held at the maximum power point voltage with occasional J-V scans taken to account for any drift in the maximum power point. It should be noted that the illumination spectrum was simulated AM 1.5 conditions, as opposed to some stability studies which use sources with low UV intensity to reduce photodegradation.

The measured PCE over time following an initial burnin period is shown in Figure 3(b). The device exhibits only small $(<5 \%)$ fluctuations over nearly $100 \mathrm{~h}$ of constant AM 1.5 illumination, demonstrating a robust resistance to photodegradation by both the nanolaminate barrier and the CQD film itself.

In summary, we have demonstrated a stable, high efficiency CQD solar cell using an ALD based barrier layer. A $70 \mathrm{~nm}$ thick nanolaminate of low temperature deposited alumina and zirconia is capable of isolating device performance from atmospheric storage and testing conditions. The encapsulated device demonstrates excellent stability through ambient storage and constant simulated solar illumination. This study is promising for the prospects of stable CQD solar cells fabricated using roll-to-roll processes.

This publication was based in part on work supported by Award KUS-11-009-21 made by King Abdullah University of Science and Technology (KAUST), by the Ontario Research Fund Research Excellence Program, and by the Natural Sciences and Engineering Research Council (NSERC) of Canada. The authors thank P. Maraghechi, R. Wolowiec, and D. Kopilovic for their help during the course of the study.

${ }^{1}$ J. Y. Kim, O. Voznyy, D. Zhitomirsky, and E. H. Sargent, Adv. Mater. 25, 4986 (2013).

${ }^{2}$ G. H. Carey, K. W. Chou, B. Yan, A. R. Kirmani, A. Amassian, and E. H. Sargent, MRS Commun. 3, 83 (2013).

${ }^{3}$ A. H. Ip, S. M. Thon, S. Hoogland, O. Voznyy, D. Zhitomirsky, R. Debnath, L. Levina, L. R. Rollny, G. H. Carey, A. Fischer, K. W. Kemp, I. J. Kramer, Z. Ning, A. J. Labelle, K. W. Chou, A. Amassian, and E. H. Sargent, Nat. Nanotechnol. 7, 577 (2012).

${ }^{4}$ X. Lan, J. Bai, S. Masala, S. M. Thon, Y. Ren, I. J. Kramer, S. Hoogland, A. Simchi, G. I. Koleilat, D. Paz-Soldan, Z. Ning, A. J. Labelle, J. Y. Kim, G. Jabbour, and E. H. Sargent, Adv. Mater. 25, 1769 (2013).

${ }^{5}$ Z. Ning, D. Zhitomirsky, V. Adinolfi, B. Sutherland, J. Xu, O. Voznyy, P. Maraghechi, X. Lan, S. Hoogland, Y. Ren, and E. H. Sargent, Adv. Mater. 25, 1719 (2013).

${ }^{6}$ M. H. Zarghami, Y. Liu, M. Gibbs, E. Gebremichael, C. Webster, and M. Law, ACS Nano 4, 2475 (2010).

${ }^{7}$ J. Tang, X. Wang, L. Brzozowski, D. A. R. Barkhouse, R. Debnath, L. Levina, and E. H. Sargent, Adv. Mater. 22, 1398 (2010).

${ }^{8}$ M. Scheele, J. H. Engel, V. E. Ferry, D. Hanifi, Y. Liu, and A. P. Alivisatos, ACS Nano 7, 6774 (2013).

${ }^{9}$ P. Poodt, D. C. Cameron, E. Dickey, S. M. George, V. Kuznetsov, G. N. Parsons, F. Roozeboom, G. Sundaram, and A. Vermeer, J. Vac. Sci. Technol. A 30, 010802 (2012).

${ }^{10}$ P. Poodt, J. van Lieshout, A. Illiberi, R. Knaapen, F. Roozeboom, and A. van Asten, J. Vac. Sci. Technol. A 31, 01 A108 (2013).

${ }^{11}$ J. R. Bakke, K. L. Pickrahn, T. P. Brennan, and S. F. Bent, Nanoscale 3, $3482(2011)$.

${ }^{12}$ S. J. Yun, Y.-W. Ko, and J. W. Lim, Appl. Phys. Lett. 85, 4896 (2004).

${ }^{13}$ S. -H. K. Park, J. Oh, C.-S. Hwang, J.-I. Lee, Y. S. Yang, and H. Y. Chu, Electrochem. Solid-State Lett. 8, H21 (2005).

${ }^{14}$ W. J. Potscavage, S. Yoo, B. Domercq, and B. Kippelen, Appl. Phys. Lett. 90, 253511 (2007).

${ }^{15}$ C.-T. Chou, P.-W. Yu, M.-H. Tseng, C.-C. Hsu, J.-J. Shyue, C.-C. Wang, and F.-Y. Tsai, Adv. Mater. 25, 1750 (2013).

${ }^{16}$ M. Fakhri, N. Babin, A. Behrendt, T. Jakob, P. Görrn, and T. Riedl, Adv. Mater. 25, 2821 (2013).

${ }^{17}$ A. Pourret, P. Guyot-Sionnest, and J. W. Elam, Adv. Mater. 21, 232 (2009).

${ }^{18}$ Y. Liu, J. Tolentino, M. Gibbs, R. Ihly, C. L. Perkins, Y. Liu, N. Crawford, J. C. Hemminger, and M. Law, Nano Lett. 13, 1578 (2013).

${ }^{19}$ Y. Liu, M. Gibbs, C. L. Perkins, J. Tolentino, M. H. Zarghami, J. Bustamante, and M. Law, Nano Lett. 11, 5349 (2011).

${ }^{20}$ A. A. Dameron, S. D. Davidson, B. B. Burton, P. F. Carcia, R. S. McLean, and S. M. George, J. Phys. Chem. C 112, 4573 (2008).

${ }^{21}$ J. Meyer, P. Görrn, F. Bertram, S. Hamwi, T. Winkler, H.-H. Johannes, T. Weimann, P. Hinze, T. Riedl, and W. Kowalsky, Adv. Mater. 21, 1845 (2009).

${ }^{22}$ P. F. Carcia, R. S. McLean, and M. H. Reilly, Appl. Phys. Lett. 97, 221901 (2010).

${ }^{23}$ C.-Y. Chang, C.-T. Chou, Y.-J. Lee, M.-J. Chen, and F.-Y. Tsai, Org. Electron. 10, 1300 (2009).

${ }^{24}$ J. W. Elam, Z. A. Sechrist, and S. M. George, Thin Solid Films 414, 43 (2002).

${ }^{25}$ J. Meyer, D. Schneidenbach, T. Winkler, S. Hamwi, T. Weimann, P. Hinze, S. Ammermann, H.-H. Johannes, T. Riedl, and W. Kowalsky, Appl. Phys. Lett. 94, 233305 (2009).

${ }^{26}$ S.-W. Seo, E. Jung, H. Chae, and S. M. Cho, Org. Electron. 13, 2436 (2012).

${ }^{27}$ D. Zhitomirsky, O. Voznyy, S. Hoogland, and E. H. Sargent, ACS Nano 7, $5282(2013)$.

${ }^{28}$ J. Gao, S. Jeong, F. Lin, P. T. Erslev, O. E. Semonin, J. M. Luther, and M. C. Beard, Appl. Phys. Lett. 102, 043506 (2013). 